\title{
ON GRONWALL'S INEQUALITY
}

\author{
S. C. CHU AND F. T. METCALF ${ }^{1}$
}

Let the functions $u$ and $h$ be continuous and nonnegative on the interval $[0,1]$; and let $c \geqq 0$ be a constant. The classical Gronwall inequality [1] states: if

$$
u(x) \leqq c+\int_{0}^{x} h(y) u(y) d y, \quad 0 \leqq x \leqq 1,
$$

then

$$
u(x) \leqq c \exp \left(\int_{0}^{x} h(y) d y\right), \quad 0 \leqq x \leqq 1 .
$$

Various linear generalizations of this inequality have been given; see, for example, [2, p. 37], [3], and [4]. In most of these cases, the upper bound for $u$ is just the solution of the equation corresponding to the integral inequality of the type (1). That is, such results are essentially comparison theorems. An abstract version of this type of comparison theorem, using lattice-theoretic methods, has been given in [5].

Presented below is a generalization of the Gronwall inequality, which contains the previous results concerning integral inequalities of the type (1).

Theorem. Let the functions $u$ and $f$ be continuous on the interval $[0,1]$; let the function $K$ be continuous and nonnegative on the triangle $0 \leqq y \leqq x \leqq 1$. If

$$
u(x) \leqq f(x)+\int_{0}^{x} K(x, y) u(y) d y, \quad 0 \leqq x \leqq 1,
$$

then

$$
u(x) \leqq f(x)+\int_{0}^{x} H(x, y) f(y) d y, \quad 0 \leqq x \leqq 1,
$$

where $H(x, y)=\sum_{i=1}^{\infty} K_{i}(x, y), 0 \leqq y \leqq x \leqq 1$, is the resolvent kernel, and the $K_{i}(i=1,2, \cdots)$ are the iterated kernels of $K$.

Received by the editors June 20, 1966.

1 The research of this author was supported in part by the Air Force Office of Scientific Research-Grant AFOSR 400-64. Present address: Department of Mathematics, University of California, Riverside. 
Proof. From (3), one has

$$
\begin{aligned}
u(x) & \leqq f(x)+\int_{0}^{x} K(x, y) f(y) d y+\int_{0}^{x} K(x, y) \int_{0}^{y} K(y, z) u(z) d z d y \\
& =f(x)+\int_{0}^{x} K_{1}(x, y) f(y) d y+\int_{0}^{x} K_{2}(x, y) u(y) d y,
\end{aligned}
$$

for $0 \leqq x \leqq 1$. The remainder of the proof is by induction and a standard estimation procedure showing the resulting series to be uniformly convergent.

The previous results, in which an explicit upper bound for $u$ was obtained, are merely those cases for which the resolvent kernel $H$ can be summed in "closed form." For example, if $K(x, y)=g(x) h(y) \geqq 0$, $0 \leqq y \leqq x \leqq 1$, then

$$
\begin{aligned}
H(x, y) & =\sum_{i=1}^{\infty} \frac{g(x) h(y)}{(i-1) !}\left(\int_{y}^{x} g(z) h(z) d z\right)^{i-1} \\
& =g(x) h(y) \exp \left(\int_{y}^{x} g(z) h(z) d z\right)
\end{aligned}
$$

since one can show by induction that each $K_{i}(i=1,2, \cdots)$ is given by the appropriate term in the sum for $H$.

\section{REFERENCES}

1. T. H. Gronwall, Note on the derivatives with respect to a parameter of the solutions of a system of differential equations, Ann. of Math. (2) 20 (1919), 292-296.

2. E. A. Coddington and N. Levinson, Theory of ordinary differential equations, McGraw-Hill, New York, 1955.

3. G. S. Jones, Fundamental inequalities for discrete and discontinuous functional equations, J. Soc. Indust. Appl. Math. 12 (1964), 43-57.

4. D. Willett, $A$ linear generalization of Gronwall's inequality, Proc. Amer. Math. Soc. 16 (1965), 774-778.

5. D. L. Hanson and Paul Waltman, $A$ note on a functional equation, J. Math. Anal. Appl. 10 (1965), 330-333.

\section{University of Delaware and} UNIVERSITY OF MARYLAND 